\title{
The Impact of Acoustics and Energy Efficiency Protocols on Comfort in the Building Industry
}

\author{
Marco Caniato ${ }^{1}$, Federica Bettarello ${ }^{2}$ \\ ${ }^{1}$ Engineering and Architecture Department, University of Trieste, Trieste, Italy \\ ${ }^{2}$ Acusticamente Designers Team, Conegliano, Italy \\ Email: mcaniato@units.it, fbettarello@acusticamente.eu
}

Received May 12, 2013; revised June 11, 2013; accepted June 18, 2013

Copyright (C) 2013 Marco Caniato, Federica Bettarello. This is an open access article distributed under the Creative Commons Attribution License, which permits unrestricted use, distribution, and reproduction in any medium, provided the original work is properly cited.

\begin{abstract}
Comfort in buildings is one of the most requested value to reach. Today, designers have to deal with so many technical features including outer appearance, air-conditioning, structural layouts, acoustic insulation and inner treatments, materials bio-compatibility, material recycling and re-use, water wasting and so on. In the same time, costumers want to buy buildings which won't cost a lot in terms of heating and cooling as in the past. Besides, every single apartment, loft, office etc., even if there are many of them in a single building, has to be very quiet. Voluntary or compulsory standards, protocols and state laws lead the designers throughout the project and in some cases to the final in field tests too. Nevertheless, different sort of calculations, leading philosophy, expected results, parameters and tags are included in order to achieve the final aims. In this paper, energy efficiency and acoustic performances of buildings are discussed, proposing and comparing designing solutions for a specific case study.
\end{abstract}

Keywords: Comfort in Buildings; Acoustic; Energy Saving; Protocol

\section{Introduction}

From the energy efficiency point of view, there are many protocols worldwide as well as regional ones. Each of them with peculiar features similar or very different one to another. They have all the same final goal (sustainability and energy saving) but with some peculiar difference in how this fact can be computed or valuated. The principal ones take into account different aspects and give rating based on the measured or predicted quality of the buildings.

\subsection{Rating Based Protocols}

\subsubsection{The Net Zero Approach}

This energy efficiency protocol has his origin in the US. It is based on the concept that the building (seen as an overall volume) has to balance consumptions and with on-site produced energy supply to the grid.

It takes into account five different parameters related to Annual Site Energy, Annual Source Energy, Annual Energy Cost and Annual Emissions.

Therefore, this protocol, balancing all this features, leads the designers and owners to accomplish specific target. What is important is that the final users have to be aware of how to use the Net Zero Building [1]. This approach is fundamental and compulsory in order to achieve, with the energy efficiency design, the final goal [2].

So, this approach aims to have a final zero energy balance within the building itself. One can perform it by the use of PV (Photo Voltaic) system commonly placed on the roof or in some additional related areas like parking. It is evident that the architectural feature of the external volume has to be realized having this point as first: huge areas for $\mathrm{PV}$ equipment in order to produce as many energy as possible. If a building has a very small roof it could by supplied by wind energy as well.

On the other hand, this facts implies that if a building may produces a lot of energy, it is not necessary to design it as a low energy consumption one, because the final zero balance is achieved anyway.

\subsubsection{LEED}

This US protocol becomes in the last years a worldwide standard so far. It focuses on different part of the building (designing and living) such as site sustainability, water waste, energy saving, inner quality, new building design.

In all the features the volume gains different scores for 
every goal reached. It implies other technical fields like acoustics, material science, environmental science and so on.

The protocol is an open procedure since different aspect are treated, updated and studied by different groups related to each other, discussing past present and future result and modifying it for new challenges.

On the other hand, building design could not focus on energy saving as itself. Therefore the volume could spend more energy, having a lower rate, but gain a higher rate for instance for the good sound insulation or using no VOCs emissions materials.

\subsubsection{Green Star}

The green star protocol is a voluntary rating system including the health of the occupants and their productivity as well as overall cost savings [3]. It takes into account the water waste as well measured or predicted energy saving. As for LEED protocol, the final score is computed taking into account many fields of the building design.

\subsection{Regional or State Protocols}

In different countries we can find some compulsory or voluntary rating systems based on worldwide ones (e.g. LEED or Green Star) or developed for the peculiar state or region because of the use of peculiar criteria may not be suitable for every part of the world [4]. As an example, the BREEAM standard has specific different version in several European countries (Germany, Spain, Norway, etc.) [5].

\subsection{Energy Saving Limited Protocols}

The last protocols are those in which only the energy saving count as final classing.

These systems are very limited in terms of computing other field instead of thermal insulation and HVAC or heating-cooling performances. No water waste, embodied energy, inner quality or innovations in design are taken into account.

On the other hand the energy designers have to focus on just this subject to claim for the final goal. Therefore they have to take care of every detail, because with these rating systems one cannot regain points with other buildings tricks or skill (like water re-use, inner quality or whatsoever). Energy saving and production with the use of renewable sources are just the two issues to cope with.

Some of these protocols are so strict that contemplate on field tests and controls from the protocol owner during the construction time and at the end of it, in order to measure and control some predicted parameters.

\subsubsection{Casaclima}

The Casaclima protocol [6] is based on energy saving. It is the most famous Italian one. It has very strict parameters to deal with as e.g. relation of building energy consumption with the climate context, choice of certified materials which can guarantee the declared performances, controls during the designing phase as well the construction one by the Casaclima inspectors and final test as Blower door tests according to EN 13829:2001 [7] for example.

This protocol has the right to promote the energy saving as a matter of fact in Italy in the last few years. Before, this topic wasn't taken seriously by the buyers, sellers, designers and national law. In the northern part of Italy, Casaclima certificate associated to the building became compulsory for selling or renting an apartment, house, etc. As for the washing machines, dishwashers, fridges etc., the buildings had their own consumption label in order to inform users of their poor or good energy saving. The class is identified by letters from $G$ (poor) to A (good) and above the last one as GOLD (very good).

In a few years no one would like to buy a $G$ or $D$ house but aim to buy $\mathrm{C}$ or B building. The builders and the designers had to cope with it, updating or changing their projects. The A class now (less than $30 \mathrm{Kw} / \mathrm{h}\left(\mathrm{m}^{2} \mathrm{a}\right)$ as a maximum energy consumption) is the minimum standard.

\subsubsection{Italian National Standard}

In Italy there is many voluntary protocols or regional compulsory ones. These make the designer classify the building according to many voluntary standards. They are almost similar in terms of final value. On the other hand, there were many different points of view on how to calculate it. In the last years a specific Italian law [8] make unifies the different standards in just one of it, make energy saving building classification compulsory. Then we have six classes from $\mathrm{F}$ or $\mathrm{G}$ (less performances) to A (high performances) with $\mathrm{C}$ class as minimum one for new buildings or renovation of them (Figure 1).

This made the building processing deeply change because costumers didn't want to buy a $G$ class house

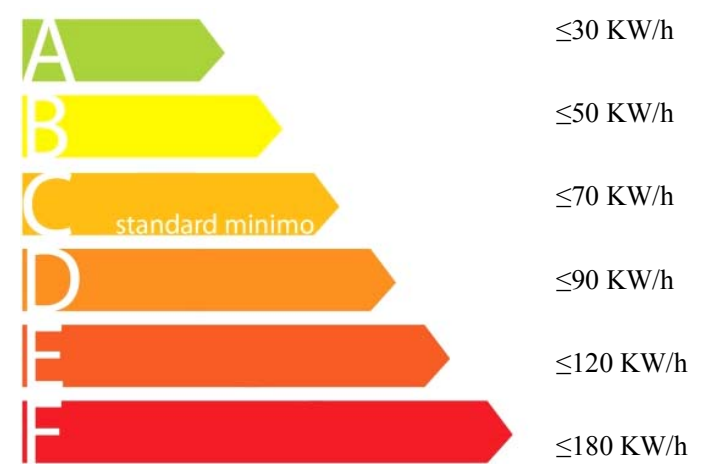

Figure 1. Energy efficiency class. 
anymore. So, designer and material sellers had to renew their proposal in order to fit new standard.

The Italian low on energy efficiency imposes that the sale of a building is always accompanied by a certificate stating the characteristics of energy consumption, in order to inform the end user about the actual annual cost of maintenance of the property. Energy consumption was evaluated by UNI TS 11300 standards [9-12]. The buildings are classified according to a scale from A (high efficiency, lower than $30 \mathrm{Kw} / \mathrm{m}^{2}$ year) to $\mathrm{G}$ (obsolete building, more than $160 \mathrm{Kw} / \mathrm{m}^{2} \cdot$ year).

From an economic point of view, an energy efficiency building can cost up to $15 \%-20 \%$ more than dissipating ones.

\subsection{Consideration on Energy Saving Protocol}

All the described rating systems above are those in which peculiar strategy or computing or territorial features are considered. Nevertheless very few of them have compulsory in field tests or strict controls in order to prove what declared. So, final results depend on the honesty of the designers and builders for the final goal. This is due to the fact that for energy saving protocol there aren't international standards or rules in order to control at the final stage the built volume. One can compute the transmittance $U$ [13] or $U_{d y n}$ [14] of outer walls or roofs but it is very difficult and expensive to measure them on the final building. What it could be measured is the air changing [7] or the HVAC or heating cooling system efficiency but these last ones are long term tests.

So at the end what it is taken into account is the final designers' declaration to certify the class or the rating. From the acoustic, static or safety point of view on field tests are available according to international standards. They are quick, reliable and affordable so they are performed most of the time to check if the declared performances match the on situ ones. No tricks or allowances are then allowed.

\section{Acoustic Requirements}

In Europe many countries developed acoustic classification of buildings. Some of these are compulsory some instead are voluntary $[15,16]$. The evolution in the construction set due to the introduction of these protocols leads the quality of the resulted buildings to a great improvement both in the design step and in the execution.

Thus, every single country composed the own standard or classification law causing big changes from one to another in terms of difference in the way of living, using and composing a building. Nevertheless in the European country, people has slightly the same living habits so the reasons for these modifications are to be imputed to country traditions or very little cooperation and discus- sion between them [17].

The Italian law on acoustic performances of building [18] defines the minimum requirements for insulation parameters of plane partitions and facades and maximum noise levels for impact sound of horizontal partitions and mechanical equipment. The recent Italian standard UNI $11367[19,20]$ propose a new method to classified the buildings in terms of acoustic insulation performance to a scale from I (quiet building) to IV (noisy building). Currently, the acoustic classification of buildings is not mandatory as the energy efficiency classification. Furthermore, it is based on in-situ tests performed and not on calculation methods. That means higher net cost for those who decide to provide, but secure results.

Acoustic classes defined by the standard, shown in Table 1, refer to the following requirements:

1) Evaluation index of normalized sound insulation of facade $\left(D_{2 m, n T, w}\right)[21]$

2) Evaluation index of apparent sound reduction index of horizontal and vertical partitions between rooms belonging to different housing units $\left(R_{w}{ }_{w}\right)[22]$;

3) Evaluation index of normalized impact sound pressure level between overlapping rooms and adjacent properties $\left(L_{n, w}\right)[23]$;

4) Sound pressure level of mechanical equipment in continuous operation $\left(L_{i c}\right)$ [24];

5) Sound pressure level of mechanical equipment in discontinuous operation $\left(L_{i d}\right)$ [24].

The will of a customer to proceed with the voluntary acoustic classification of a building is driven in most cases by two typical reasons: to be sure that the finished project meets at least the requirements of the Italian law to avoid future unpleasant and especially in a period of Italian estate sector crisis, demonstrate better performances of the construction so that a possible buyer would prefer his property instead of another.

There are big and small difference from the Italian Acoustic Classification and the European ones [25]. Generally speaking, we can state that the minimum law values for the five considered parameters are significantly lower (3 dB at least). On the other hand, the voluntary buildings classification in the II and I classes rises

Table 1. Descriptors useful for noise classification of real estate.

\begin{tabular}{cccccc}
\hline \multirow{5}{*}{ Class } & \multicolumn{5}{c}{ Acoustic parameters } \\
\cline { 2 - 6 } & $D_{2 m, n T, w}(\mathrm{~dB})$ & $R^{\prime}{ }_{w}(\mathrm{~dB})$ & $L_{n, w}^{\prime}(\mathrm{dB})$ & $L_{i c}(\mathrm{~dB})$ & $L_{i d}(\mathrm{~dB})$ \\
\hline I & $\geq 43$ & $\geq 56$ & $\leq 53$ & $\leq 25$ & $\leq 30$ \\
II & $\geq 40$ & $\geq 53$ & $\leq 58$ & $\leq 28$ & $\leq 33$ \\
III & $\geq 37$ & $\geq 50$ & $\leq 63$ & $\leq 32$ & $\leq 37$ \\
IV & $\geq 32$ & $\geq 45$ & $\leq 68$ & $\leq 37$ & $\leq 42$ \\
\hline
\end{tabular}


up the minimum values at European levels. Thus, this is the hopefully future if the final aim is the inner comfort as for energy efficiency.

\section{The Building Project: A Case Study}

The analyzed project consists of a flat block composed of two blocks separated by seismic joint, which are developed on a basement used for cars and four floors above ground, for a total of 23 units. The apartments are not serial, but with the internal composition very similar (typically: kitchen, living room, two bedrooms and two bathrooms). The partitions are composed with thermic bricks of different thickness, fibrous material coupled with plasterboard inserted in the cavities, extruded polystyrene foam for thermal insulation of radial heating panel and roof. Plaster was chosen as finishing; a resilient material was used in order to obtain the floating floor system for the reduction of the impact sound pressure level (Figures 2-5). Brick walls were chosen in order to supply lightweight structures (compared with concrete ones) which could provide mass for dynamic thermal characteristics and good acoustic properties. As mechanical equipment systems, low noise level and high insulation performance were prescribed and then suggested measures for the realization of the internal passages of pipes with suitable size and geometry that ensures quiet operations. All critical points such as thermal

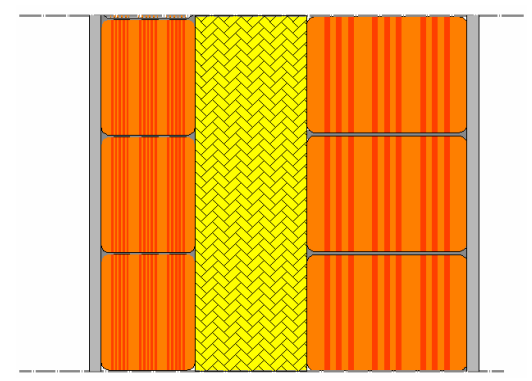

Figure 2. Outer wall; calculated thermal performance: $U=$ $0.2 \mathrm{~W} / \mathrm{m}^{2} \mathrm{~K}$; calculated acoustic performance: $R_{w}=57 \mathrm{~dB}$.

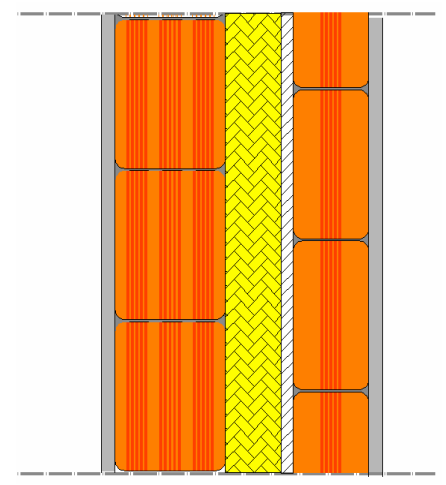

Figure 3. Internal vertical partitions; calculated acoustic performance: $R_{w}=56 \mathrm{~dB}$. and acoustic bridges have been treated in detail in order to avoid realization problems (e.g. Figures 6 and 7).

\subsection{Energy Saving and Acoustic Classification of the Case Study Flatblock}

From the energetic point of view, the compulsory classification linked to the building is, has said before, a theoretical computation taking into account the sun orientation, external transmittance of the walls (and floors), performance and type of HVAC and renewable energy production. All this, combined with the proper and unpredictable use, lead us to a "A" energy saving classifi-

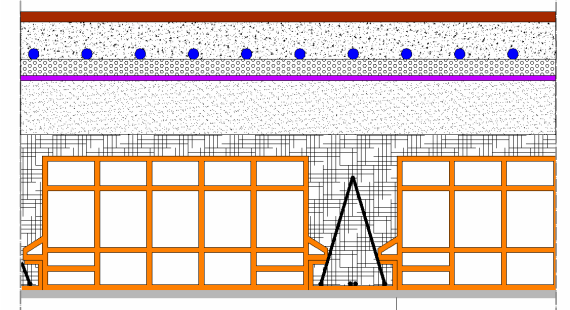

Figure 4. Internal horizontal partitions; calculated acoustic performances: $R_{w}=55 \mathrm{~dB}, L_{n, w}=49 \mathrm{~dB}$.

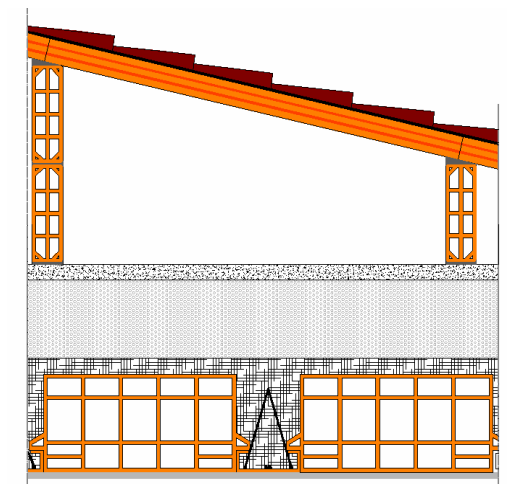

Figure 5. Roof; calculated thermal performance: $U=0.2$ W/m² K; calculated acoustic performance: $R_{w}=55 \mathrm{~dB}$.

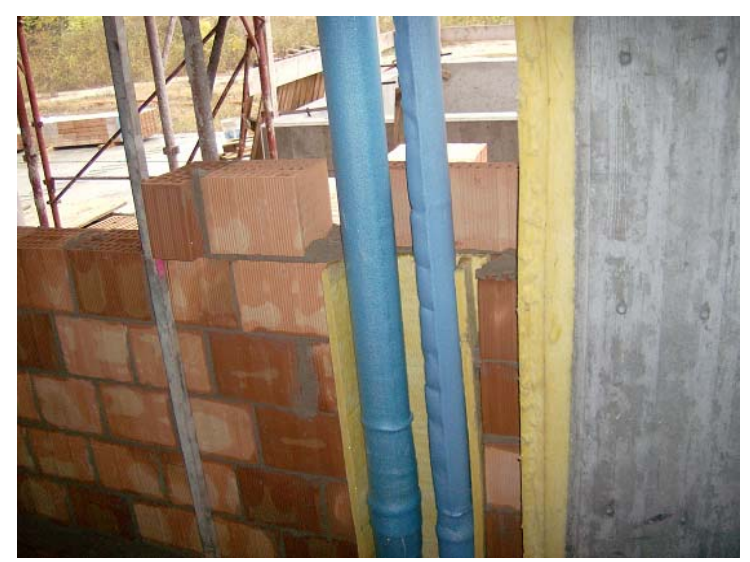

Figure 6. Thermal and acoustic bridge avoiding using proper plumbing sheath and fibrous material. 


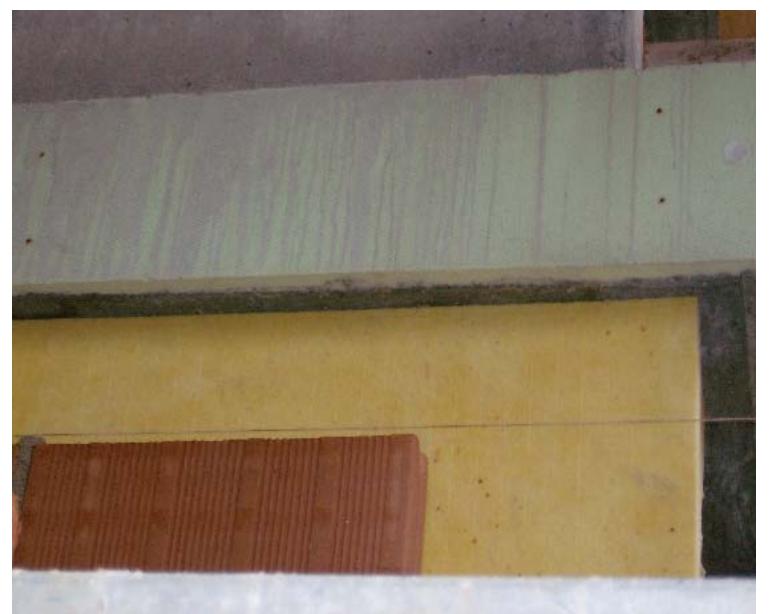

Figure 7. Thermal bridge avoiding using polystyrene and fiber in outer wall-floor joints.

cation. On the other hand, in order to obtain the acoustic classification of the flat block, a lot of in-situ measurements were conducted, choosing first of all the apartments-sample units that could represent the typical unit of the flat block. The plan type of the building is shown in Figure 8; the red perimeter identifies the sample units chosen for acoustic performances tests, according to [20].

For each chosen apartment were performed many tests: the evaluation index of apparent sound reduction index for horizontal partitions of 4 different rooms ( 2 to the upper level and 2 to the lower level), the evaluation index of apparent sound reduction index for vertical partitions of 4 different rooms, the evaluation index of normalized impact sound pressure level for horizontal partitions of 4 different rooms, the evaluation index of normalized sound insulation of facade of 5 different rooms, two level measurements on discontinuous mechanical equipment (toilet discharge systems) and a level measurement on continuous mechanical equipment (controlled mechanical ventilation). The measurements of acoustical parameters were conducted following the standards ISO 140 [21-23]. Considering the importance of in situ measurements for the acoustic classification of the flatblock $[26,27]$, all the measurements were verified with the method suggested by ISO 10052 standard [28]. All the index values were determined following the ISO 717-1 [29] e 717-2 [30] standards. For the sound insulation index of all the measured façades have been obtained very good values: from 40 to $46 \mathrm{~dB}$; then for the parameter $D_{2 m, n T, w}$ has been reached the class I. Also in terms of normalized impact sound pressure level index very good values for each room have been obtained: from 46 to $51 \mathrm{~dB}$; thus also for the parameter $L_{n, w}$ has been reached the class I. For the exhaust systems and controlled mechanical ventilation, have been obtained sound pressure level values between $20 \mathrm{~dB}$ (A) and 28

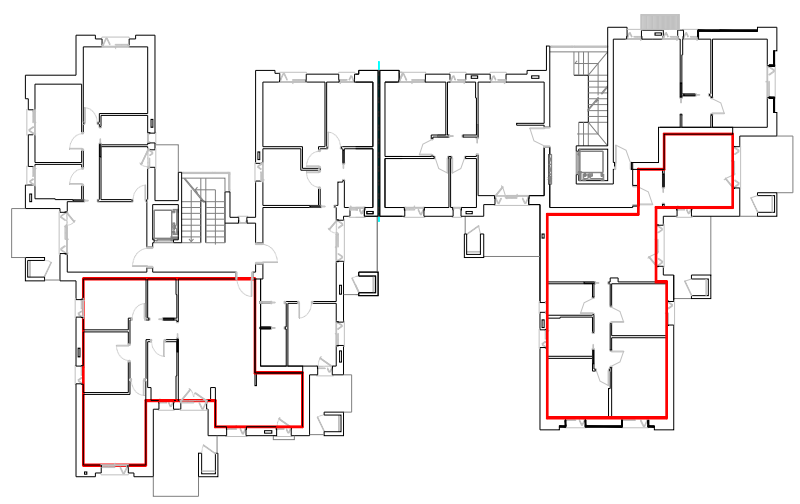

Figure 8. Building plan with identification sample units chosen for acoustic performances test.

$\mathrm{dB}$ (A) for the first one and between $25 \mathrm{~dB}$ (A) and 28 $\mathrm{dB}(\mathrm{A})$ for the second one, reaching the class I for both parameters. For the apparent sound reduction index of the internal partitions, the first measurements reported very variable performances, with values too much low compared with the calculated acoustic performances. Further investigations have allowed us to understand which problems were incurred in the production of vertical partitions. Part of the walls with no insulation has been reconstructed. Subsequent verification measures have demonstrated the obtainment of class I also for the parameter $R^{\prime}{ }_{w}$.

\section{Concluding Remarks}

An overview of different energy saving protocols and acoustic classification of building was proposed, comparing them for the peculiar use. A case study was presented to give an example of what to do in applied case. Classifying methods are always good main to compare different buildings even in different country, climates, etc. This motivates both designers and managers to improve more performing solution in order to satisfy market requests. Nevertheless, the substantial difference between the realization of an energy efficiency classification and an acoustic classification of a building resides in the disappointing expenditure due to the realization of the big campaign of acoustic measurements necessary for the compilation of the latter. However, it is sure that the method of in situ verification measurements necessary to proceed to the acoustic classification of the building is not only more realistic but also can help in case of specific problems not easy to identify only with a design method.

\section{Acknowledgements}

The authors and cousins would like to thank Antonietta for everything she taught us. 


\section{REFERENCES}

[1] C. Kibert and R. Srinivasan, "Net Zero: A Novel Approach for Setting Sustainability Targets for Built Environment," Advances in Building Science, Madras, 2013, pp. 11-28.

[2] M. Caniato, V. Fonovich and S. Longhi, "Risparmio Eneergetico e Comfort Abitativo-Istruzioni per 1'Uso," Alinea Ed, Florence, 2012.

[3] T. J. McCarthy and H. Rasekth, "21st Century Sustainable Building Design in Australia," Advances in Building Science, Madras, 2013, pp. 51-65.

[4] S. W. Lang, "Progress in Energy-Efficiency Standards for Residential Buildings in China," Energy and Buildings, Vol. 36, No. 12, 2004, pp. 1191-1196. doi:10.1016/j.enbuild.2003.09.014

[5] B. K. Nguyen and H. Altan, "Comparative Review of Five Sustainable Rating Systems," Procedia Engineering, Vol. 21, 2011, pp. 376-386. doi:10.1016/j.proeng.2011.11.2029

[6] N. Lantschner, "CasaClima Il Piacere di Abitare," Athesia, Bozen, 2008.

[7] "Thermal Performance of Buildings-Determination of Air Permeability of Buildings-Fan Pressurization Method," EN 13829, 2001.

[8] “Actuation of European Standard 2002/91/CE on Energy Saving in Buildings and Following Modifications and Integrations," Decree 311, 2006.

[9] "Determinazione del Fabbisogno di Energia Termica Dell'Edificio per la Climatizzazione Estiva ed Invernale," UNI TS 11300-1, 2010.

[10] "Determinazione del Fabbisogno di Energia Primaria e dei Rendimenti per la Climatizzazione Invernale e per la Produzione di Acqua Calda Sanitaria," UNI TS 11300-2, 2010.

[11] "Determinazione del Fabbisogno di Energia Primaria e dei Rendimenti per la Climatizzazione Estiva," UNI TS 11300-3, 2010.

[12] "Utilizzo di Energie Rinnovabili e di Altri Metodi di Generazione per la Climatizzazione Invernale e per la Produzione di Acqua Calda Sanitaria," UNI TS 11300-4, 2010.

[13] "Building Components and Building Elements - Thermal Resistance and Thermal Transmittance-Calculation Method," ISO 6946, 2007.

[14] "Thermal Performance of Building Components-Dynamic Thermal Characteristics - Calculation Methods," ISO 13786, 2007.

[15] G. Cellai, P. Fausti, E. Nannipieri and S. Secchi, "Il Contesto Costruttivo Italiano Rispetto ai Sistemi Europei di Classificazione Acustica: Analisi di Risultati Sperimentali in Edifici Residenziali," Proceedings of Italian Acoustic Association Congress, Milan, 11-13 June 2008.

[16] E. Nannipieri and S. Secchi, "The Evolution of Acoustic
Comfort in Italian Houses," The Journal of Building Acoustics, Vol. 19, No. 2, 2012, pp. 99-118.

[17] K. Hagberg and D. Bard, "Sound Insulation Descriptors in Europe-Special Rules Complicate Harmonization within Light Weight Industry," Proceedings of ISSA2010 Sustainability in Acoustics, Auckland, 29-31 August 2010.

[18] "Determination of Passive Acoustic Requirements of Buildings," Decree of the President of the Ministers Council of 5th December, 1997.

[19] "Building Acoustics-Acoustic Classification of Building Units-Evaluation Procedure and in Situ Measurements," UNI 11367, 2010.

[20] "Building Acoustic_-Acoustic Classification of Building Units-Evaluation Procedure of Non-Serial Buildings," UNI 11444, 2012.

[21] "Acoustics - Measurement of Sound Insulation in Buildings and of Building Elements_-Part 5: Field Measurements of Airborne Sound Insulation of Façade Elements and Façades," ISO 140-5, 1998.

[22] "Acoustics-Measurement of Sound Insulation in Buildings and of Building Elements_-Part 4: Field Measurements of Airborne Sound Insulation between Rooms," ISO 140-4, 1998.

[23] "Acoustics-Measurement of Sound Insulation in Buildings and of Building Elements-Part 7: Field Measurements of Impact Sound Insulation of Floors," ISO 140-7, 1998.

[24] "Acoustics-Measurement Of Sound Pressure Level from Service Equipment in Buildings-Engineering Method," ISO 16032, 2005.

[25] F. Bettarello, P. Fausti, V. Baccan and M. Caniato, "Impact Sound Pressure Level Performances of Basic Beam Floor Structures," The Journal of Building Acoustics, Vol. 17, No. 3, 2010, pp. 305-316.

[26] M. Caniato and F. Bettarello, "High Thermal and Acoustic Performances on New Building According to Strict Protocols," Advances in Building Science, Madras, 2013, pp. 173-180.

[27] M. Caniato, F. Bettarello and V. Baccan, "La Misura Degli Indici $\mathrm{R}_{\mathrm{w}}, \mathrm{L}_{\mathrm{n}, \mathrm{w}}$ e $\mathrm{D}_{2 \mathrm{~m}, \mathrm{nt}, \mathrm{w}}$ : Confronto in Opera tra $\mathrm{i}$ Metodi Proposti Dalle Norme UNI EN ISO 140 e UNI EN ISO 10052," Proceedings of Italian Acoustic Association Congress, Rome, 4-6 July 2012.

[28] "Acoustics - Field Measurements of Airborne and Impact Sound Insulation and of Service Equipment SoundSurvey Method," ISO 10052, 2004.

[29] "Acoustics - Rating of Sound Insulation in Buildings and of Building Elements-Part 1: Airborne Sound Insulation," ISO 717-1, 1996.

[30] "Acoustics - Rating of Sound Insulation in Buildings and of Building Elements-Part 2: Impact Sound Insulation," ISO 717-2, 1996. 